\title{
RESEARCH
}

Open Access

\section{Levels of CXCL13 and sICAM-1 correlate with disease activity score in patients with rheumatoid arthritis treated with tocilizumab}

Katie Tuckwell ${ }^{1 *}$, Cem Gabay², Thierry Sornasse ${ }^{1}$, Ruediger Paul Laubender ${ }^{3}$, Jianmei Wang ${ }^{4}$ and Michael J. Townsend ${ }^{1}$

\begin{abstract}
Background: Tocilizumab (TCZ), a humanized monoclonal antibody against the interleukin- 6 receptor, has been proven to be a safe and effective treatment for rheumatoid arthritis (RA). Because RA is a heterogenous disease and patient response to treatments can vary, identifying characteristics that predict which patients are more likely to respond to TCZ is important for optimal patient care. Serum levels of C-X-C motif chemokine ligand 13 (CXCL13) and soluble intercellular adhesion molecule-1 (sICAM-1) have been associated with response to TCZ in patients with RA.

Objectives: To evaluate the association of CXCL13 and sICAM-1 with disease activity and response to TCZ in patients with early RA and those with inadequate response to disease-modifying antirheumatic drugs (DMARD-IR).

Methods: Baseline and week 24 serum CXCL13 and sICAM-1 levels were measured using available patient samples from the FUNCTION (early RA) and LITHE (DMARD-IR) trials. Correlations between CXCL13 and sICAM-1 levels and Disease Activity Score in 28 joints calculated with erythrocyte sedimentation rate (DAS28-ESR) at baseline and between change in CXCL13 and sICAM-1 and change in DAS28-ESR at week 24 were estimated. CXCL13 and sICAM-1 changes from baseline to week 24 were compared between treatment arms. The effects of TCZ treatment and baseline DAS28ESR, CXCL13 and sICAM-1 levels on DAS28-ESR remission and 50\% improvement per the American College of Rheumatology (ACR50) response at week 24 were determined.

Results: Overall, 458 patients from FUNCTION and 287 patients from LITHE were included. Correlation of baseline serum CXCL13 and sICAM-1 levels with DAS28-ESR was weak to moderate. CXCL13 and sICAM-1 levels decreased significantly at week 24 in TCZ-treated patients in both the early-RA and DMARD-IR populations. CXCL13 and sICAM-1 changes correlated moderately to weakly with DAS28-ESR changes at week 24 in both populations. The treatment regimen, but not baseline CXCL13 and sICAM-1 levels, had a significant effect on the likelihood of DAS28-ESR remission and ACR50 response.
\end{abstract}

Conclusions: Although CXCL13 and sICAM-1 are modestly associated with RA disease activity, they do not predict response to TCZ in all RA populations.

Keywords: Biomarkers, CXCL13, Rheumatoid arthritis, Tocilizumab, sICAM-1

\footnotetext{
* Correspondence: Tuckwell.katie@gene.com

'Genentech, Inc., 1 DNA Way, South San Francisco, CA 94080, USA

Full list of author information is available at the end of the article
}

(c) The Author(s). 2019 Open Access This article is distributed under the terms of the Creative Commons Attribution 4.0 International License (http://creativecommons.org/licenses/by/4.0/), which permits unrestricted use, distribution, and reproduction in any medium, provided you give appropriate credit to the original author(s) and the source, provide a link to the Creative Commons license, and indicate if changes were made. The Creative Commons Public Domain Dedication waiver (http://creativecommons.org/publicdomain/zero/1.0/) applies to the data made available in this article, unless otherwise stated. 


\section{Introduction}

Rheumatoid arthritis (RA) is a pathologically heterogeneous disease, with variability between patients in the number of affected joints, antibody titers, serum cytokine levels, and severity of joint damage. Histological and molecular heterogeneity in synovial tissue of patients with RA has also been demonstrated [1-3]. Genome-wide expression analysis of synovial tissues from a large RA cohort demonstrated distinct molecular and cellular phenotypes, which reflect the heterogeneity present in the RA synovium [4]. Some of the clinical and treatment response heterogeneity may be explained by myeloid-, lymphoid-, and fibroiddominant synovial subtypes of RA [5]. Although a wide range of treatment options have shown clinical benefit in patients with RA, it is unknown which patients will respond to specific treatments. Synovial tissue is often unavailable before the initiation of treatment; therefore, the use of serum biomarkers to predict which patients will respond to a specific treatment is an area of interest for rheumatologists.

The biomarker $\mathrm{C}-\mathrm{X}-\mathrm{C}$ motif chemokine ligand 13 (CXCL13) is a B-cell chemoattractant that is expressed by follicular dendritic cells in secondary lymphoid tissue and ectopic germinal centers [6]. Studies have shown a correlation between synovial tissue expression of CXCL13 and CXCL13 serum levels [7] and suggested that CXCL13 has a role in RA pathogenesis related to accumulation of $B$ cells in inflamed synovium [8]. CXCL13 has been shown to be associated with the lymphoid phenotype of patients with RA [4]. Soluble intercellular adhesion molecule-1 (sICAM-1) is an adhesion molecule that is upregulated in a variety of cell types in response to TNF $\alpha$ signaling and has been shown to be associated with the myeloid synovial phenotype in patients with RA [4]. CXCL13 (lymphoid) and sICAM-1 (myeloid) were shown to differentially predict response in patients who received the anti-IL-6 receptor antibody tocilizumab (TCZ) as monotherapy and had prior inadequate response to methotrexate (MTX) [4]. In clinical practice, patients vary in terms of duration of RA and previous therapy. Studies are needed to analyze the association of biomarkers with disease activity and treatment response in varied populations of patients who receive TCZ either as monotherapy or in combination with MTX for the treatment of RA. This study aimed to determine whether there is an association of CXCL13 and sICAM-1 with disease activity and response to TCZ in patients with early RA and those with inadequate response to disease-modifying antirheumatic drugs (DMARD-IR).

\section{Materials and methods}

Patient inclusion and exclusion criteria and methods for the FUNCTION and LITHE trials were described previously $[9,10]$. Patients in FUNCTION had moderate to severe RA of $\leq 2$ years' duration (early RA) and had not previously received MTX or biologic agents [9]. Patients in LITHE had moderate to severe RA for $\geq 6$ months with an inadequate response to MTX (DMARD-IR) [10]. The FUNCTION and LITHE study protocols were approved by an ethics committee or institutional review board at each participating center before the start of the study. All patients provided written informed consent in accordance with the Declaration of Helsinki.

For the present study, patients from FUNCTION and LITHE placebo (PBO) + MTX arms, TCZ $8 \mathrm{mg} / \mathrm{kg}$ monotherapy arm (FUNCTION only), and TCZ $8 \mathrm{mg} /$ $\mathrm{kg}+$ MTX arms were selected based on baseline and week 24 serum sample availability. Patients from the TCZ $4 \mathrm{mg} / \mathrm{kg}$ arms were not selected. Serum CXCL13 and sICAM-1 levels were measured using a commercial ELLA (automated enzyme-linked immunosorbent assay) and performed in accordance with the relevant national and international regulations and guidance by Microcoat Biotechnologie GmbH (Bernried am Starnberger See, Germany). The CXCL13 assay (ProteinSimple, San Jose, CA, USA) was conducted using $25 \mu \mathrm{L}$ of serum samples, which were diluted two-fold. The lower limit of quantification as calculated for undiluted serum ranged from 1.14 to $1.58 \mathrm{pg} / \mathrm{mL}$ depending on the kit lot of the assay and the upper limit of quantification was $12,220 \mathrm{pg} / \mathrm{mL}$ for all kit lots of the assay. The precision, as determined from the analysis of quality control samples, was satisfactory throughout the analytical study and ranged from 0.124 to $10.211 \%$ for low quality control (LQC) and from 0.384 to $10.153 \%$ for high quality control (HQC). The mean concentration of LQC was $20.387 \mathrm{pg} / \mathrm{mL}$ with a coefficient of variation (CV) of $7.4 \%$. The mean concentration of HQC was $974.169 \mathrm{pg} / \mathrm{mL}$ with a CV of $5.5 \%$.

The sICAM-1 assay (ProteinSimple, San Jose, CA, USA) was conducted using $5 \mu \mathrm{L}$ of serum samples, which were diluted 100-fold. The lower limit of quantification as calculated for undiluted serum was $410 \mathrm{pg} / \mathrm{mL}$ and the upper limit of quantification as calculated for undiluted serum was $1,563,000 \mathrm{pg} / \mathrm{mL}$. The precision, as determined from the analysis of quality control samples, was satisfactory throughout the analytical study and ranged from 0.064 to $17.640 \%$ for LQC and from 0.160 to $11.660 \%$ for HQC. The mean concentration of LQC was $114.531 \mathrm{pg} / \mathrm{mL}$ with a CV of $9.7 \%$. The mean concentration of HQC was $5240.573 \mathrm{pg} / \mathrm{mL}$ with a CV of $6.8 \%$.

\section{Statistical analysis}

Baseline clinical characteristics were compared between the FUNCTION biomarker population and the LITHE biomarker population using the Welch $t$ test on transformed data; $P$ values $<0.05$ were considered statistically significant. Correlations between CXCL13 or sICAM-1 levels and DAS28-ESR scores were evaluated according 
to the Pearson correlation coefficient. Changes in CXCL13 and sICAM-1 from baseline to week 24 were compared between treatment arms using the Welch $t$ test. The effect of treatment and baseline DAS28-ESR, CXCL13, and sICAM-1 on the likelihood of DAS28-ESR remission and 50\% improvement per the American College of Rheumatology (ACR50) response at week 24 was estimated via logistic regression. Log transformation was used for the biomarker values to ensure a more normal distribution of the data. Results were not adjusted for multiple testing.

\section{Results}

Overall, 458 of 869 patients from FUNCTION (TCZ 8 $\mathrm{mg} / \mathrm{kg}$ monotherapy, $n=157$; TCZ $8 \mathrm{mg} / \mathrm{kg}+\mathrm{MTX}, n=$ 160; PBO + MTX, $n=141$ ) and 287 of 791 patients from LITHE (TCZ 8 mg/kg + MTX, $n=137$; PBO + MTX, $n=$ 150) were included. Mean disease duration in FUNCTION (early RA) was significantly shorter than in LITHE (DMARD-IR; 0.45 vs 8.65 years; $P<0.0001$ ); mean ESR at baseline was significantly higher in patients in FUNCTION than in those in LITHE (Table 1). At baseline, CXCL13 levels correlated moderately with DAS28-ESR in the early-RA population $(r=0.36 ; P<0.0001)$ and weakly in the DMARD-IR population $(r=0.21 ; P=0.0003)$ (Fig. 1). Correlation between SICAM-1 levels and DAS28ESR was low in both the early-RA $(r=0.14 ; P=0.0029)$ and DMARD-IR populations $(r=0.17 ; P=0.0040)$.

In the early-RA population, baseline CXCL13 correlated weakly with all 4 components of DAS28-ESR (tender joint count, $r=0.2$; swollen joint count [SJC], $r=0.24$; ESR, $r=$ 0.34; Patient Global Assessment [PGA], $r=0.24 ; P<$ 0.000031 for all), whereas sICAM-1 only correlated weakly with SJC $(r=0.15 ; P<0.0031)$ and $\operatorname{ESR}(r=0.17 ; P<$ 0.00031). In the DMARD-IR population, baseline CXCL13 correlated weakly with ESR $(r=0.20 ; P<0.0031)$ and PGA
( $r=0.22 ; P<0.00031$ ), and sICAM-1 did not significantly correlate with any of the DAS28-ESR components.

The proportion of patients who achieved ACR50 response and DAS28-ESR remission by study population and treatment arm are shown in Fig. 2. Response to treatment was similar between patients in the present biomarker analysis and the intent-to-treat (ITT) populations in the FUNCTION and LITHE trials (data not shown). CXCL13 decreased significantly at week 24 in all treatment arms in both the early-RA and DMARD-IR populations, with the greatest reductions observed in the TCZ + MTX and TCZ monotherapy arms (Fig. 3a). In the early-RA population, the effect of TCZ monotherapy on CXCL13 was similar to that of TCZ + MTX. sICAM-1 decreased significantly at week 24 in the TCZ monotherapy arm in patients with early RA and the TCZ + MTX arms in both the early-RA and DMARD-IR populations but not in the $\mathrm{PBO}+\mathrm{MTX}$ arms (Fig. 3b).

Change in CXCL13 correlated moderately with change in DAS28-ESR at week 24 in both the early-RA and DMARD-IR populations $(r=0.33 ; P<0.0001$ for both) (Fig. 4). Change in sICAM-1 correlated moderately with change in DAS28-ESR at week 24 in the DMARD-IR population ( $r=0.26 ; P=0.0002)$ but weakly in the earlyRA population $(r=0.16 ; P=0.0005)$. Although the treatment arm had a significant effect on the likelihood of DAS28-ESR remission and achievement of ACR50, the effects of baseline levels of CXCL13 and sICAM-1 were not significant (Additional file 1: Table S1). Furthermore, biomarker categories based on high vs low baseline CXCL13 and sICAM-1 levels did not predict response to TCZ or MTX in the early-RA or DMARD-IR populations (data not shown).

We assessed differences between extreme responders and nonresponders in the FUNCTION and LITHE trials by defining highest DAS28 response as those patients

Table 1 Baseline Clinical Characteristics

\begin{tabular}{|c|c|c|c|c|c|c|c|c|}
\hline \multirow{2}{*}{$\begin{array}{l}\text { Baseline Clinical } \\
\text { Characteristics, } \\
\text { Mean (SD) }\end{array}$} & \multirow{2}{*}{$\begin{array}{l}\text { FUNCTION } \\
\text { Biomarker } \\
\text { Population } \\
(n=458)\end{array}$} & \multirow{2}{*}{$\begin{array}{l}\text { LITHE } \\
\text { Biomarker } \\
\text { Population } \\
(n=287)\end{array}$} & \multirow[t]{2}{*}{$P$ Value* } & \multicolumn{3}{|c|}{ FUNCTION ITT Population } & \multicolumn{2}{|l|}{ LITHE ITT Population } \\
\hline & & & & $\begin{array}{l}\mathrm{TCZ} 8 \mathrm{mg} / \mathrm{kg} \\
\text { Monotherapy } \\
(n=292)\end{array}$ & $\begin{array}{l}\text { TCZ } 8 \mathrm{mg} / \mathrm{kg}+\mathrm{MTX} \\
(n=290)\end{array}$ & $\begin{array}{l}\mathrm{PBO}+\mathrm{MTX} \\
(n=287)\end{array}$ & $\begin{array}{l}\text { TCZ } 8 \mathrm{mg} / \mathrm{kg}+\mathrm{MTX} \\
(n=398)\end{array}$ & $\begin{array}{l}\mathrm{PBO}+\mathrm{MTX} \\
(n=393)\end{array}$ \\
\hline Disease duration, years & $0.45(0.50)$ & $8.65(7.80)$ & $<0.0001$ & $0.5(0.48)$ & $0.5(0.53)$ & $0.4(0.48)$ & $9.3(8.2)$ & $9.0(8.1)$ \\
\hline TJC68 & $28.8(16.9)$ & $29.0(15.5)$ & 0.5594 & $28.7(16.3)$ & $28.7(16.7)$ & $27.4(16.5)$ & $29.3(15.2)$ & $27.9(14.8)$ \\
\hline SJC66 & $17.3(11.5)$ & $16.4(9.5)$ & 0.4889 & $16.5(10.1)$ & $17.6(12.4)$ & $16.2(10.4)$ & $17.3(9.5)$ & $16.6(9.2)$ \\
\hline DAS28-ESR & $6.7(1.0)$ & $6.5(0.9)$ & 0.0013 & $6.7(1.0)$ & $6.7(1.1)$ & $6.6(1.0)$ & $6.6(1.0)$ & $6.5(1.0)$ \\
\hline $\mathrm{ESR}, \mathrm{mm} / \mathrm{h}$ & $53.0(28.8)$ & $43.1(21.4)$ & $<0.0001$ & $51.3(28.4)$ & $52.8(30.2)$ & $50.4(26.8)$ & $46.3(24.8)$ & $46.4(24.7)$ \\
\hline $\mathrm{CRP}, \mathrm{mg} / \mathrm{dL}$ & $2.5(2.8)$ & $2.1(2.5)$ & 0.2702 & $2.5(3.2)$ & $2.6(3.0)$ & $2.3(2.7)$ & $2.3(2.6)$ & $2.2(2.5)$ \\
\hline PGA, 100-mm VAS & $63.0(18.8)$ & $62.6(16.9)$ & 0.7807 & $63.9(18.1)$ & $63.6(18.1)$ & $62.7(17.3)$ & $62.7(16.9)$ & $63.1(17.3)$ \\
\hline
\end{tabular}

CRP C-reactive protein, DAS28-ESR Disease Activity Score in 28 joints calculated with erythrocyte sedimentation rate; DMARD-IR inadequate response to diseasemodifying antirheumatic drugs; ESR erythrocyte sedimentation rate; ITT intent to treat; PGA Patient Global Assessment; RA rheumatoid arthritis; SJC66 swollen joint count in 66 joints; TJC68 tender joint count in 68 joints; VAS visual analog scale

* $P$ value is for the comparison between the FUNCTION biomarker population and the LITHE biomarker population 


\section{a Patients in the FUNCTION Trial (early RA)}
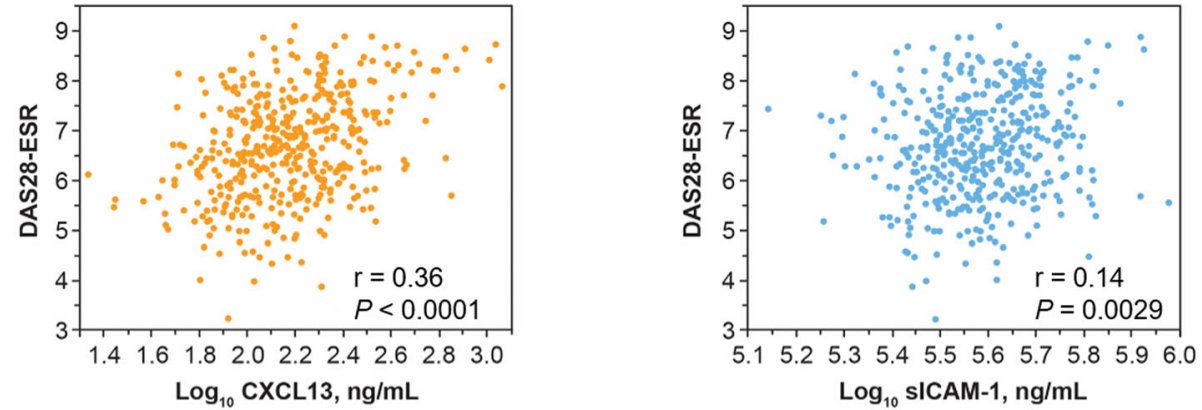

\section{b Patients in the LITHE Trial (DMARD-IR)}
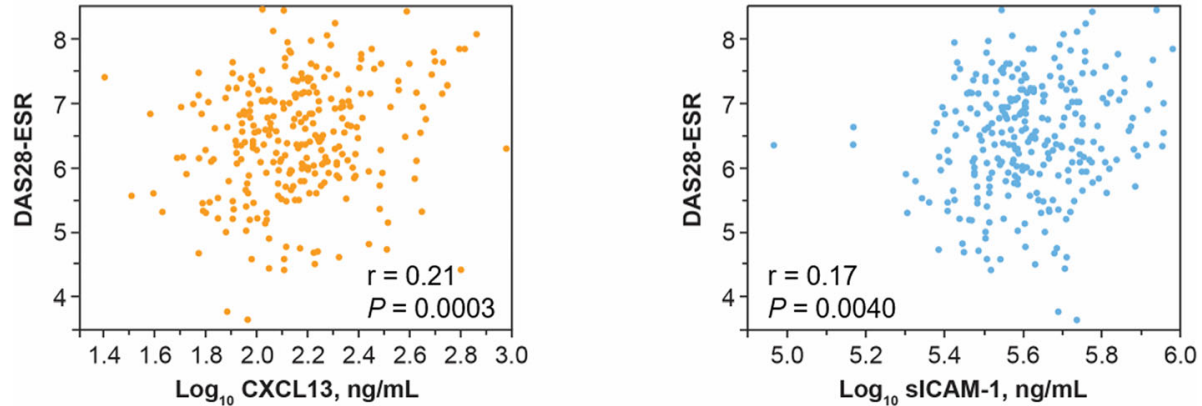

Fig. 1 Correlation Between Serum CXCL13 and sICAM-1 Levels and DAS28-ESR at Baseline. a Patients in the FUNCTION trial (early RA). b Patients in the LITHE trial (DMARD-IR). CXCL13, C-X-C motif chemokine ligand 13; DAS28-ESR, Disease Activity Score in 28 joints calculated with erythrocyte sedimentation rate; DMARD-IR, inadequate response to disease-modifying antirheumatic drugs; RA, rheumatoid arthritis; sICAM-1, soluble intercellular adhesion molecule-1

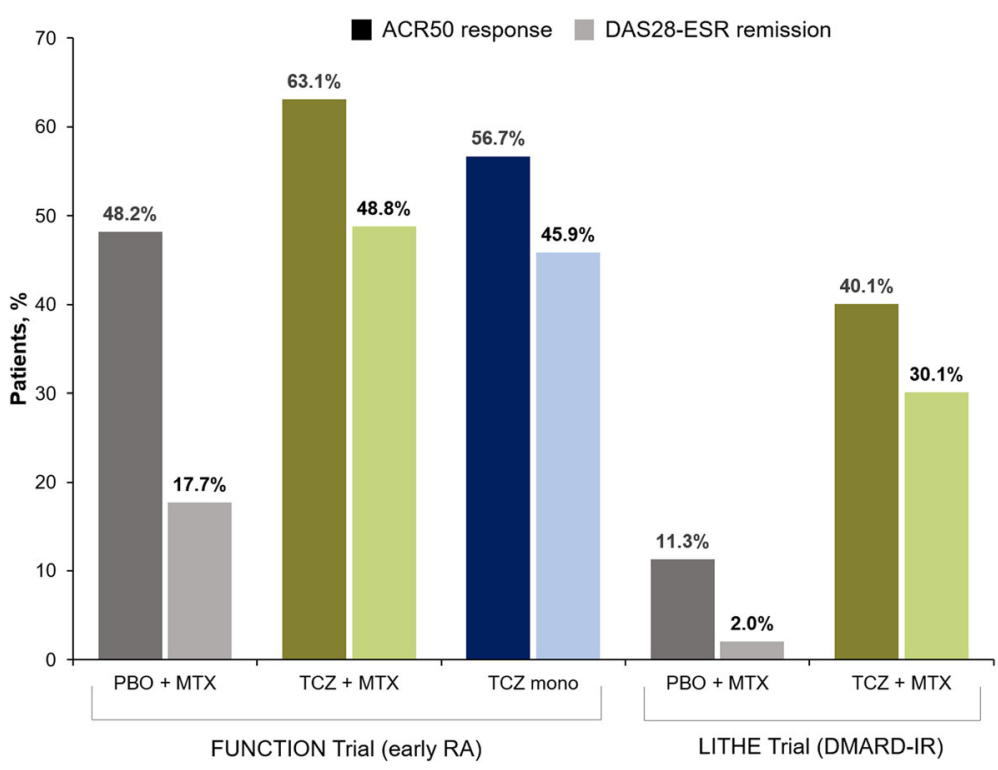

Fig. 2 Proportion of Patients Who Achieved ACR50 Response and DAS28-ESR Remission at Week 24 by Study and Treatment Arm. ACR50, 50\% improvement per the American College of Rheumatology; DAS28-ESR, Disease Activity Score in 28 joints calculated with erythrocyte sedimentation rate; DMARD-IR, inadequate response to disease-modifying antirheumatic drugs; mono, monotherapy; MTX, methotrexate; PBO, placebo; RA, rheumatoid arthritis; TCZ, tocilizumab 
a. CXCL13

FUNCTION (early RA) $\quad$ LITHE (DMARD-IR)

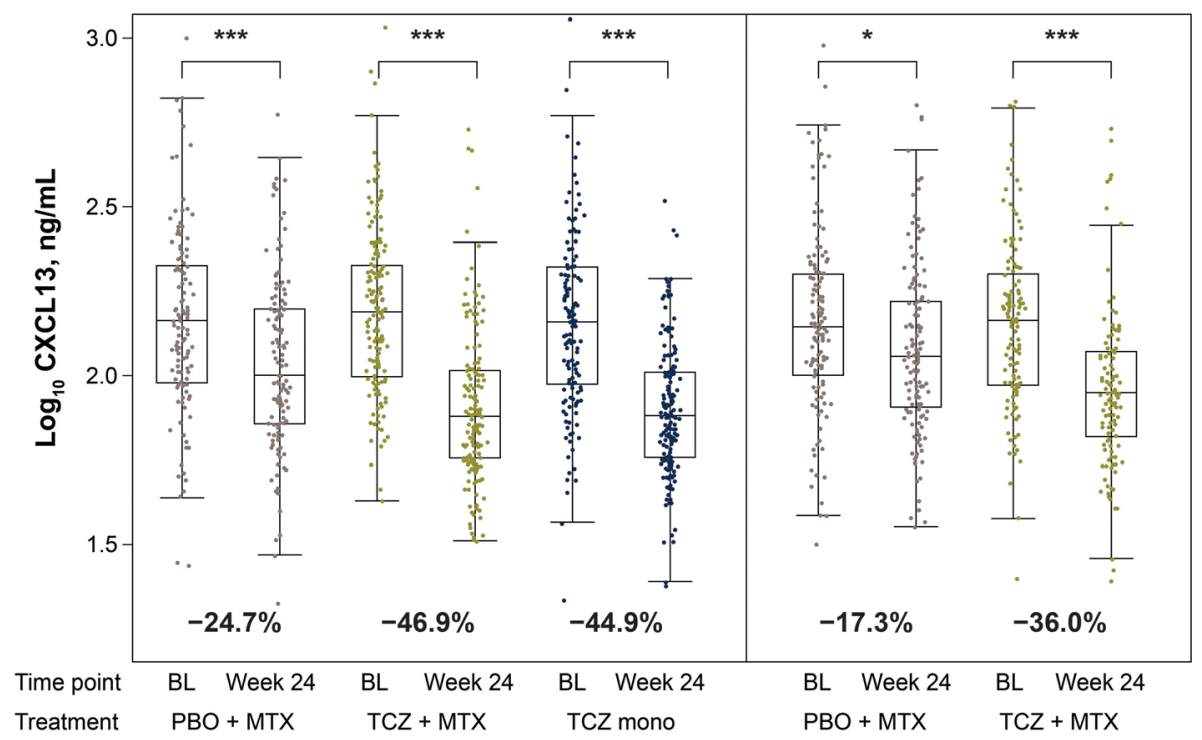

b. SICAM-1

FUNCTION (early RA)

LITHE (DMARD-IR)

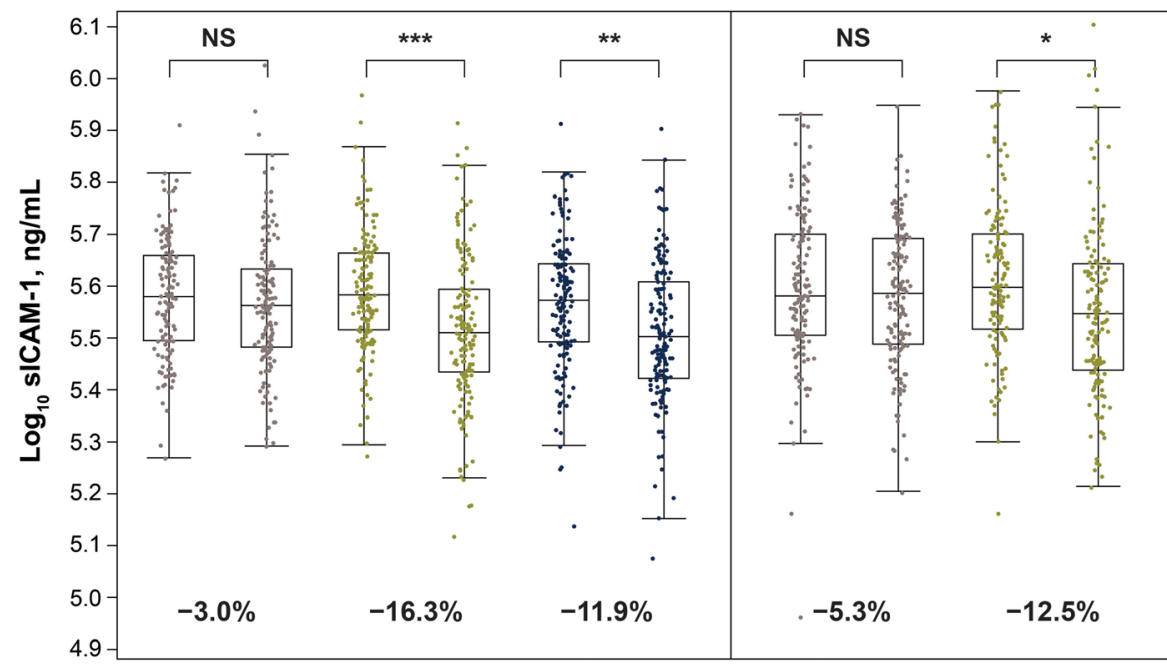

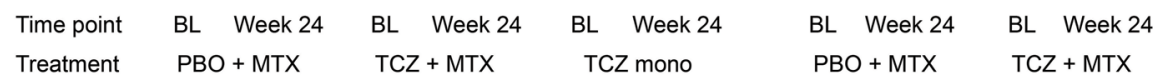

Fig. 3 Change in CXCL13 and sICAM-1 From Baseline to Week 24 by Study and Treatment Arm. a CXCL13. b sICAM-1. BL, baseline; CXCL13, C-X-C motif chemokine ligand 13; DAS28-ESR, Disease Activity Score in 28 joints calculated with erythrocyte sedimentation rate; DMARD-IR, inadequate response to disease-modifying antirheumatic drugs; MTX, methotrexate; NS, not significant; PBO, placebo; RA, rheumatoid arthritis; sICAM-1, soluble intercellular adhesion molecule-1; TCZ, tocilizumab. ${ }^{*} P<0.01$. ${ }^{* *} P<0.001 .{ }^{* * *} P<0.0001$

who achieve DAS28 remission status at 24 weeks and defining lowest DAS28 response as those patients who failed to achieve a decrease in DAS28 of at least 0.6. In the FUNCTION trial, patients receiving TCZ who achieved remission had a mean (SD) sICAM1 level of
$398.89(99.62) \mathrm{ng} / \mathrm{ml}$ and CXCL13 level of 162.64 (109.69) $\mathrm{pg} / \mathrm{ml}$, whereas patients who failed to achieve a DAS28 response had a sICAM1 level of 397.34 (117.33) $\mathrm{ng} / \mathrm{ml}$ and CXCL13 level of 102.63 (33.75) pg/ml. Similarly in the LITHE trial, patients receiving TCZ who 
a Patients in the FUNCTION Trial (early RA)
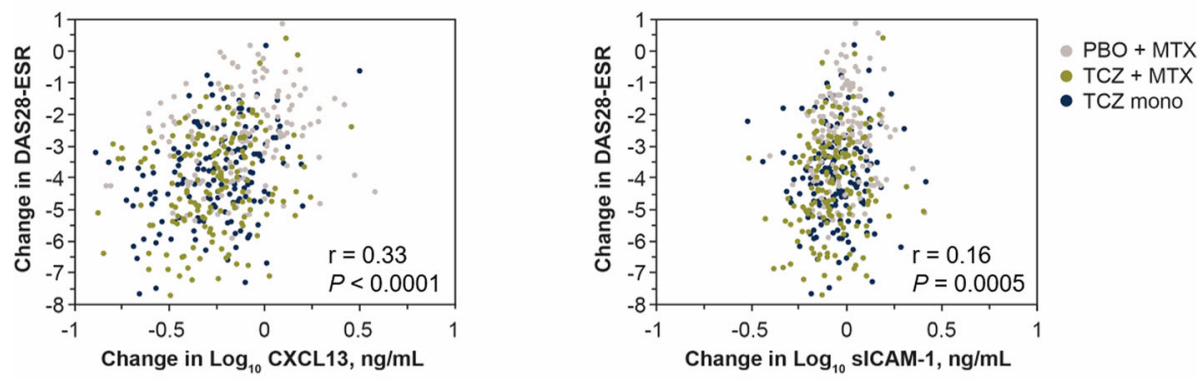

b Patients in the LITHE Trial (DMARD-IR)
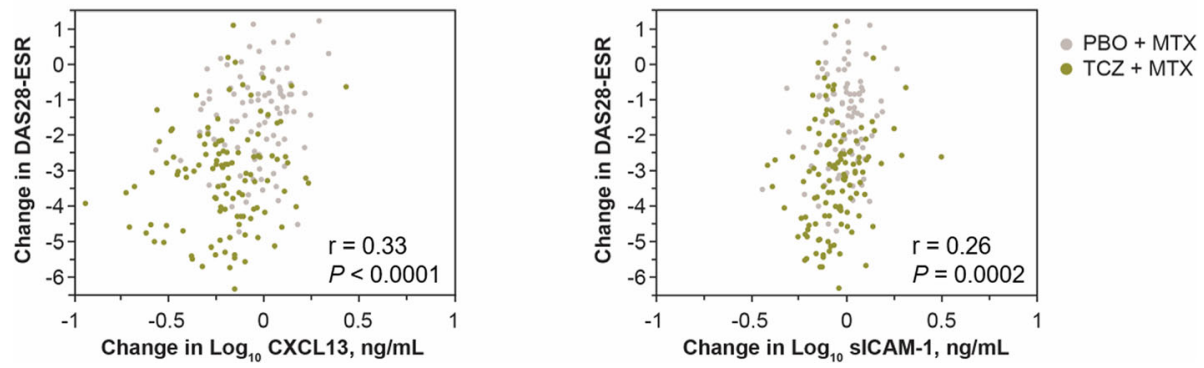

Fig. 4 Correlation Between Change in Serum Levels of CXCL13 and sICAM-1 and Change in DAS28-ESR at Week 24. CXCL13, C-X-C motif chemokine ligand 13; DAS28-ESR, Disease Activity Score in 28 joints calculated with erythrocyte sedimentation rate; DMARD-IR, inadequate response to disease-modifying antirheumatic drugs; MTX, methotrexate; PBO, placebo; RA, rheumatoid arthritis; sICAM-1, soluble intercellular adhesion molecule-1; TCZ, tocilizumab

achieved remission had a mean (SD) sICAM1 level of $421.28(139.49) \mathrm{ng} / \mathrm{ml}$ and CXCL13 level of 165.09 (104.84) $\mathrm{pg} / \mathrm{ml}$, whereas patients who failed to achieve a DAS28 response had a sICAM1 level of 426.94 (150.03) $\mathrm{ng} / \mathrm{ml}$ and CXCL13 level of 176.13 (153.22) $\mathrm{pg} / \mathrm{ml}$. Therefore, even in patients with extremes of DAS28 response, baseline levels of CXCL13 and sICAM1 did not differ significantly.

A higher proportion of patients in the ITT population of the LITHE trial were receiving glucocorticoids at baseline (PBO + MTX, 70\%; TCZ + MTX, 62\%) [10] than patients in the ITT population in the FUNCTION trial (PBO + MTX, 38\%; TCZ + MTX, 33\%; TCZ mono, 40\%) [9]. Inclusion criteria related to glucocorticoids were similar between studies $[9,10]$.

\section{Discussion}

In the present study, the association of CXCL13 with disease activity in RA was stronger in early-RA patients than in DMARD-IR patients. Prior exposure to DMARDs may have affected baseline CXCL13 levels, despite patients having active RA. Furthermore, a study of DMARD-naïve patients with early RA ( $<3$ months) proposed that high levels of CXCL13 possibly indicated recent inflammation [11]. Changes in CXCL13 and, to a lesser extent, sICAM-1 correlated significantly with changes in DAS28-ESR at week 24. Notably, in early-RA patients, the effect of TCZ monotherapy on changes in CXCL13 was similar to that observed with TCZ + MTX. The decrease in CXCL13 with disease activity was consistent with a previous study analyzing CXCL13 in patients treated with rituximab [7].

In the DMARD-IR patients, CXCL13 levels decreased significantly in patients in the $\mathrm{PBO}+\mathrm{MTX}$ group. We suspect that this decrease in CXCL13 level is due to the anti-inflammatory effect of methotrexate treatment in these patients, despite their previously reported DMARD-IR status. This effect on the levels of an inflammatory biomarker could reflect better MTX treatment adherence due to the closer medical monitoring while enrolled in a clinical trial.

The results of the present study differed from those of a study of patients with RA (MTX-IR) from the ADACTA trial, which demonstrated that patients with high baseline CXCL13 levels were more likely to respond to TCZ monotherapy than patients with high sICAM-1 levels [4]. The effect of MTX on CXCL13 and sICAM-1 may have contributed to the discordant study results. More patients in the present study received TCZ + MTX $(n=297)$ than TCZ monotherapy $(n=157)$. However, a study of patients 
with inadequate response to tumor necrosis factor inhibitors who received sarilumab + DMARDs was also unable to fully replicate the biomarker results from ADACTA [12].

Although this study is among the first to evaluate the serum biomarkers CXCL13 and sICAM-1 in early-RA and DMARD-IR patients who received TCZ, it does have limitations. This study used available samples only, which may have resulted in a biased population. However, DAS28 and ACR50 results were similar between patients in the present biomarker study and the ITT populations in the FUNCTION and LITHE trials. In addition, Clinical Disease Activity Index values were not calculated, although they may have been informative because changes in ESR may explain some of the association between decreased CXCL13 and sICAM-1 and decreased disease activity.

\section{Conclusions}

In summary, baseline CXCL13 and sICAM-1 levels did not predict response to $\mathrm{TCZ}$ at week 24, suggesting that although CXCL13 and sICAM-1 were modestly associated with RA disease activity, they do not predict response to TCZ in all RA populations.

\section{Supplementary information}

Supplementary information accompanies this paper at https://doi.org/10. 1186/s42358-019-0097-1.

Additional file 1: Table S1. Online Resource 1 Multivariate Logistic Regression Model for DAS28-ESR Remission and ACR50 Response at Week 24

\section{Abbreviations}

ACR50: 50\% improvement per the American College of Rheumatology; CV: Coefficient of variation; CXCL13: C-X-C motif chemokine ligand 13; DAS28-ESR: Disease Activity Score in 28 joints calculated with erythrocyte sedimentation rate; DMARD-IR: Inadequate response to disease-modifying antirheumatic drugs; ESR: Erythrocyte sedimentation rate; HQC: Higher quality control; ITT: Intent to treat; LQC: Lower quality control; MTX: Methotrexate; PGA: Patient global assessment; RA: Rheumatoid arthritis; sICAM-1: Soluble intercellular adhesion molecule-1; SJC: Swollen joint count; TCZ: Tocilizumab

\section{Acknowledgements}

Support for third-party writing assistance for this manuscript, furnished by Nicola Gillespie, DVM, of Health Interactions, Inc., was provided by Genentech, Inc.

\section{Authors' contributions}

$\mathrm{KT}$ analyzed and interpreted study data and contributed to the preparation and writing of the manuscript. CG interpreted the findings and contributed to writing of the manuscript. TS analyzed and interpreted study data and contributed to the preparation and review of the manuscript. RPL and JW contributed to the preparation and review of the manuscript. MJT analyzed and interpreted study data and contributed to the preparation and writing of the manuscript. All authors read and approved the final manuscript.

\section{Funding}

This study was funded by F. Hoffmann-La Roche Ltd. and Genentech, Inc The funder was involved in the design of the study and collection, analysis, and interpretation of data and in the medical writing support for this manuscript.

\section{Availability of data and materials}

Qualified researchers may request access to individual patient level data analyzed for this study through the clinical study data request platform (www.clinicalstudydatarequest.com). Further details on Roche's criteria for eligible studies are available here (https://clinicalstudydatarequest.com/ Study-Sponsors/Study-Sponsors-Roche.aspx). For further details on Roche's Global Policy on the Sharing of Clinical Information and how to request access to related clinical study documents, see here (https://www.roche. com/research_and_development/who_we_are_how_we_work/clinical_trials/ our_commitment_to_data_sharing.htm).

\section{Ethics approval and consent to participate}

The FUNCTION and LITHE study protocols were approved by an ethics committee or institutional review board at each participating center before the start of the study. All patients provided written informed consent in accordance with the Declaration of Helsinki.

\section{Consent for publication}

Not applicable.

\section{Competing interests}

K Tuckwell and M Townsend are employees of Genentech, Inc. C Gabay has received research funding from Roche, Pfizer, and AB2 Bio and fees as consultant and speaker from Roche, Pfizer, AbbVie, Novartis, and Sanofi. T Sornasse was an employee of Genentech, Inc., at the time of the study. R Laubender is an employee of Roche Diagnostics $\mathrm{GmbH}$. J Wang is an employee of Roche Products Ltd.

\section{Author details}

${ }^{1}$ Genentech, Inc., 1 DNA Way, South San Francisco, CA 94080, USA. ${ }^{2}$ University Hospital of Geneva, Geneva, Switzerland. ${ }^{3}$ Roche Diagnostics, Penzberg, Germany. ${ }^{4}$ Roche Products, Welwyn Garden City, UK.

Received: 21 May 2019 Accepted: 15 November 2019

Published online: 04 December 2019

References

1. Lindstrom TM, Robinson WH. Biomarkers for rheumatoid arthritis: making it personal. Scand J Clin Lab Invest Suppl. 2010;242:79-84.

2. van Baarsen $L G$, Bos $C L$, van der Pouw Kraan $T C$, Verweij $C L$. Transcription profiling of rheumatic diseases. Arthritis Res Ther. 2009;11(1):207.

3. van der Pouw Kraan TC, van Gaalen FA, Huizinga TW, Pieterman E, Breedveld FC, Verweij CL. Discovery of distinctive gene expression profiles in rheumatoid synovium using CDNA microarray technology: evidence for the existence of multiple pathways of tissue destruction and repair. Genes Immun. 2003;4(3):187-96.

4. Dennis G Jr, Holweg CT, Kummerfeld SK, Choy DF, Setiadi AF, Hackney JA, et al. Synovial phenotypes in rheumatoid arthritis correlate with response to biologic therapeutics. Arthritis Res Ther. 2014;16(2):R90.

5. Humby F, Kelly S, Hands R, Rocher V, DiCicco M, Ng N, et al. Use of ultrasound-guided small joint biopsy to evaluate the histopathologic response to rheumatoid arthritis therapy: recommendations for application to clinical trials. Arthritis Rheumatol (Hoboken, NJ). 2015;67(10):2601-10.

6. Corsiero E, Bombardieri M, Manzo A, Bugatti S, Uguccioni M, Pitzalis C. Role of lymphoid chemokines in the development of functional ectopic lymphoid structures in rheumatic autoimmune diseases. Immunol Lett. 2012;145(1-2):62-7.

7. Rosengren S, Wei N, Kalunian KC, Kavanaugh A, Boyle DL. CXCL13: a novel biomarker of B-cell return following rituximab treatment and synovitis in patients with rheumatoid arthritis. Rheumatology (Oxford, England). 2011; 50(3):603-10.

8. Armas-Gonzalez E, Dominguez-Luis MJ, Diaz-Martin A, Arce-Franco M, Castro-Hernandez J, Danelon G, et al. Role of CXCL13 and CCL20 in the recruitment of $B$ cells to inflammatory foci in chronic arthritis. Arthritis Res Ther. 2018;20(1):114 -018-1611-2.

9. Burmester GR, Rigby WF, van Vollenhoven RF, Kay J, Rubbert-Roth A, Kelman $A$, et al. Tocilizumab in early progressive rheumatoid arthritis: FUNCTION, a randomised controlled trial. Ann Rheum Dis. 2016;75(6): 1081-91.

10. Kremer JM, Blanco R, Brzosko M, Burgos-Vargas R, Halland AM, Vernon E, et al. Tocilizumab inhibits structural joint damage in rheumatoid arthritis 
patients with inadequate responses to methotrexate: results from the double-blind treatment phase of a randomized placebo-controlled trial of tocilizumab safety and prevention of structural joint damage at one year. Arthritis Rheum. 2011:63(3):609-21.

11. Greisen SR, Schelde KK, Rasmussen TK, Kragstrup TW, Stengaard-Pedersen K, Hetland ML, et al. CXCL13 predicts disease activity in early rheumatoid arthritis and could be an indicator of the therapeutic 'window of opportunity'. Arthritis Res Ther. 2014;16(5):434-014 -0434-z.

12. Gabay C, Msihid J, Zilberstein M, Paccard C, Lin Y, Graham NMH, et al. Identification of sarilumab pharmacodynamic and predictive markers in patients with inadequate response to TNF inhibition: a biomarker substudy of the phase 3 TARGET study. RMD Open. 2018;4(1):e000607-2017 eCollection 2018.

\section{Publisher's Note}

Springer Nature remains neutral with regard to jurisdictional claims in published maps and institutional affiliations.

Ready to submit your research? Choose BMC and benefit from:

- fast, convenient online submission

- thorough peer review by experienced researchers in your field

- rapid publication on acceptance

- support for research data, including large and complex data types

- gold Open Access which fosters wider collaboration and increased citations

- maximum visibility for your research: over $100 \mathrm{M}$ website views per year

At BMC, research is always in progress.

Learn more biomedcentral.com/submissions 